\title{
A tecnologia assistiva SCALA na promoção de narrativas de sujeitos com Transtorno do Espectro Autista sobre as suas experiências escolares e o autismo
}

\author{
Ivanise Gomes de Souza Bittencourt ${ }^{1}$, Neiza de Lourdes Frederico F umes $^{2}$ \\ ${ }^{1}$ Escola de Enfermagem e Farmácia- Universidade Federal de Alagoas (UFAL)- \\ Maceió- AL- Brasil \\ ${ }^{2}$ Centro de Educação- Universidade Federal de Alagoas (UFAL)- Maceió- AL- Brasil \\ ivanisegsb@gmail.com, neizaf@yahoo.com
}

\begin{abstract}
This study aims to discuss the contribution of Alternative Communication System for Literacy People with Autism (SCALA) in promoting subjects narratives with autistic spectrum disorder (ASD) about their school experiences and autism. This assistive technology was developed in 2009 by researchers from the Federal University of Rio Grande do Sul (UFRGS) and in subsequent years acquired new versions adding a module of visual narratives to build stories on web platforms and android / tablet, which was used by the research subjects in the construction of their stories.

Resumo

O presente estudo tem por objetivo discutir a contribuição do Sistema de Comunicação Alternativa para Letramento de Pessoas com Autismo (SCALA) na promoção de narrativas de sujeitos com Transtorno do Espectro Autista (TEA) sobre as suas experiências escolares e o autismo. Essa tecnologia assistiva foi desenvolvida em 2009 por pesquisadores da Universidade Federal do Rio Grande do Sul (UFRGS) e nos anos subsequentes adquiriu novas versões acrescentando um módulo de narrativas visuais para a construção de histórias nas plataformas web e android/tablet, o qual foi utilizado pelos sujeitos da pesquisa na construção das suas histórias.
\end{abstract}

\section{Introdução}

Esse estudo discute a contribuição do SCALA na promoção de narrativas de sujeitos com TEA sobre as suas experiências escolares e o autismo.

Conhecer as experiências escolares direciona reflexões sobre o seu processo de inclusão e escolarização, sobre como esse ser social se constituiu, aprendeu e se desenvolveu a partir das relações e interações que lhes foram possibilitadas e das práticas em que foi inserido (Chiote, 2013). É fundamental, conforme Charlot (2005), compreender como o sujeito categoriza, organiza seu mundo, como ele dá sentido à sua experiência e especialmente à sua experiência escolar. Para esse autor, "aprender faz sentido por referência à história do sujeito, suas expectativas, suas referências, sua concepção de vida, suas relações com os outros, à imagem que tem de si e à que quer dar de si aos outros" (p. 72).

Entretanto, os sujeitos com TEA apresentam especificidades na comunicação, por isso utilizou-se o SCALA como apoio nesse processo. Dessa forma, esse estudo objetivou apresentar as contribuições dessa ferramenta na promoção de narrativas desses sujeitos. 
V Congresso Brasileiro de Informática na Educação (CBIE 2016)

Anais do XXVII Simpósio Brasileiro de Informática na Educação (SBIE 2016)

Considerando as dificuldades que comumente os sujeitos com TEA apresentam para se comunicarem, as quais interferem na sua autonomia, interação e desenvolvimento, foi utilizado o SCALA, uma tecnologia assistiva que está disponível nas plataformas web e android/tablet, onde o módulo utilizado foi o de narrativas visuais (construção de histórias), para que pudessem contextualizar as suas experiências escolares e a imagem que possuem do autismo, e para promover as suas narrativas e formas de expressão.

\section{O Transtorno do Espectro Autista}

Os sujeitos com Transtorno do Espectro Autista (TEA) apresentam especificidades na comunicação, comportamento, interação social e nos processos de aprendizado e desenvolvimento, de acordo com a Lei 12.764 de 27 de dezembro de 2012. Esta, institui a Política Nacional de Proteção dos Direitos da Pessoa com TEA, e considera a pessoa com transtorno do espectro autista aquela portadora de síndrome clínica caracterizada por deficiência persistente e clinicamente significativa da comunicação e da interação social, falência em desenvolver e manter relações apropriadas ao seu nível de desenvolvimento (Brasil, 2012). Para efeitos legais, esta lei reconhece as pessoas com TEA como pessoas com deficiência (Brasil, 2012), as quais têm impedimentos de longo prazo de natureza física, mental, intelectual ou sensorial, que podem obstruir sua participação plena e efetiva na sociedade em igualdades de condições com as demais pessoas (Brasil, 2009).

Por isso, devem ser assegurados às pessoas com TEA os apoios necessários para seu pleno desenvolvimento. De maneira que esses sujeitos possam se apropriar tanto dos conhecimentos disponíveis no mundo quanto das formas e das possibilidades de novas produções (Farias; Maranhão; Cunha, 2008).

O termo autismo de origem grega "autós" significando "si mesmo", foi utilizado em 1911, pelo psiquiatra suíço Eugen Bleuler, que difundiu o termo designando-o como perda do contato com a realidade e consequente dificuldade ou impossibilidade de comunicação (Marfinati, Abrão, 2014; Lima 2014).

Léo Kanner, psiquiatra austríaco naturalizado americano, em 1943, observou onze crianças que passaram por sua consulta e escreveu sobre "Os distúrbios autísticos do contato afetivo", identificando como traço fundamental do autismo a incapacidade para relacionar-se normalmente com as pessoas e as situações desde o princípio de suas vidas (Lima, 2014). Nessa mesma década, Hans Asperger, médico austríaco, de acordo com Klin (2006) descreveu os casos de quatro crianças que tinham dificuldade em se integrar socialmente em grupos. Publicou em 1944 sua tese de doutorado intitulada "A Psicopatia autista na infância" apresentando como questão central o transtorno no relacionamento com o ambiente a seu redor, onde as características autistas seriam persistentes. Também em 1944, outro médico austríaco Bruno Bettelheim desenvolveu a hipótese de que a criança encontra no isolamento autístico um recurso de intolerância ao mundo exterior, de uma experiência negativa vivida na relação com a mãe e seu ambiente familiar. A causa do autismo estava relacionada ao não desejo da existência do filho, a incapacidade de lhe oferecer o afeto necessário, onde essa convicção tornou-se alvo de críticas nos anos seguintes (Lima, 2014).

Na década de 50 destaca-se Frances Tustin, psicanalista inglesa que trabalhou vinte anos com crianças autistas em sua clínica, considerando-as "crianças encapsuladas" fundada na ideia da paralisação do desenvolvimento psicológico. Defendeu que que alguns pacientes apresentavam "núcleos autísticos impenetráveis que os tornam inacessíveis ao contato" (Korbivche, 2007, p. 56). 
Em 1964, o psicólogo americano Bernard Rimland, como descreve Lima (2014) apontou para a falta de evidências e demonstrações empíricas das teses quanto a atribuição do autismo ao fator afetivo definindo-o como uma disfunção cognitiva. A psiquiatra inglesa Lorna Wing em 1981 introduziu o conceito de Espectro Autista como resultado do reconhecimento do autismo como um espectro de condições (Klin, 2006).

Vários pesquisadores contribuíram para a construção do histórico do autismo ao longo das décadas, outras referências foram o CID-10 (Classificação Estatística Internacional de Doenças e Problemas Relacionados à Saúde) da Organização Mundial de Saúde e Organização das Nações Unidas e o DSM (Diagnostic and Statistical Manual of Mental Disordes) Manual Diagnóstico e Estatístico de Transtornos Mentais. No CID10, o autismo infantil é classificado como um transtorno caracterizado por um desenvolvimento anormal ou alterado, manifestado antes dos três anos de idade, e apresentando uma perturbação característica do funcionamento em cada um dos três domínios seguintes: interações sociais, comunicação, comportamento focalizado e repetitivo (Cid-10, 2008). O DSM passou por edições onde as considerações sobre o autismo sofreram alterações.

Em sua mais atualizada versão, o DSM V de 2013 define que: Transtorno Autista ou Autismo Clássico, Transtorno de Ásperger, Transtorno Invasivo do Desenvolvimento (Sem Outra Especificação) também conhecido como autismo atípico, Síndrome de Rett e Transtorno Desintegrativo da Infância, não mais existirão como diagnósticos distintos, mas como um grupo dos "Transtornos do Espectro Autista", unificados, localizados no grupo dos "Transtornos do Neurodesenvolvimento" (Apa, 2013). O termo "espectro" engloba o autismo da infância, autismo de Kanner, autismo de alto funcionamento, autismo atípico, transtorno invasivo do desenvolvimento sem outra especificação, transtorno desintegrativo da infância e transtorno de Asperger. E as suas variações analisadas por graus (Leve, Moderado e Severo). A Síndrome de Rett tornou-se uma entidade própria, deixando de ser parte do espectro do autismo (Apa, 2013).

\section{A Tecnologia Assistiva SCALA}

O SCALA tem como objetivo apoiar o desenvolvimento do letramento de pessoas com autismo (Bez et al., 2013a). O primeiro protótipo foi desenvolvido em 2009, por pesquisadores do grupo de Tecnologia em Educação para Inclusão e Aprendizagem em Sociedade (TEIAS) da UFRGS, para computadores desktop e nos anos subsequentes adquiriu novas versões para funcionar na web e em dispositivos móveis como celular, tablets, entre outros (Bez; Passerino, 2012). O referido software é gratuito e foi desenvolvido sob a licença Creative Commons.

Em 2011 o SCALA 2.0 (http://scala.ufrgs.br) iniciou a proposta multiplataforma, de conteúdo aberto, para atender a demanda de aplicativos para tablet. Possui dois módulos, prancha e histórias, e apresenta mais de 4.000 (quatro mil) imagens, divididas nas categorias (pessoas, objetos, natureza, ações, alimentos, sentimentos, qualidades) além do ícone "minhas imagens" onde o usuário pode inserir imagens próprias no sistema (Passerino et al., 2013).

As pranchas de comunicação, de acordo com Passerino et al. (2013) são recursos de tecnologia assistiva que facilitam a comunicação entre pessoas com déficit de comunicação e outros participantes. Além de contribuir para a interação e autonomia dos sujeitos. Nesse estudo, optou-se por utilizar o módulo narrativas visuais que serve para construção de histórias, o qual apresenta flexibilidade na elaboração. Este módulo disponibiliza diversificados layouts, inserção de imagens edição das mesmas, escolha de 
V Congresso Brasileiro de Informática na Educação (CBIE 2016)

Anais do XXVII Simpósio Brasileiro de Informática na Educação (SBIE 2016)

cores e cenários (Passerino et al., 2013). Agrega conforme Bez et al. (2013a) a categoria "balões" de conversação, permitindo a inserção de pequenos diálogos, como também é possível escrever a história ou gravá-la, a história pode ser reproduzida pelo sintetizados de voz que pode ler o que foi digitado.

Uma experiência da utilização do SCALA, no ano de 2012, em uma turma de Educação Infantil de uma escola da rede privada de Porto Alegre, onde dois alunos com TEA estavam incluídos, proporcionou interação, entusiasmo facilitação da comunicação destes com os demais alunos e integração ao ambiente escolar, (Bez et al., 2013b), "comprovando-se o sistema como uma efetiva ferramenta de apoio a comunicação" (Bez et al., 2013a, p. 1).

Dessa forma, o módulo de narrativas visuais do SCALA foi apresentado aos sujeitos participantes da pesquisa para que conhecessem todos os seus recursos de forma a promover a construção de suas histórias sobre as suas experiências escolares e o autismo.

Pois segundo Passerino, Ávila e Bez (2010, p. 1), sujeitos com autismo podem apresentar dificuldades em contar histórias, visto que "nem todos possuem as competências de comunicação capazes de possibilitar a sua interação com o meio", ou seja a apropriação da linguagem oral e escrita.

\section{Método}

Este estudo é de caráter qualitativo. Nessa perspectiva, Gray $(2012$, p.135) afirma que "[...] o papel do pesquisador é obter um panorama profundo, intenso e "holístico" do contexto em estudo, muitas vezes envolvendo a interação dentro das vidas cotidianas de pessoas, grupos, comunidades e organizações".

De um modo mais particular, será realizada a análise narrativa que "é a análise de uma história contada cronologicamente, com um foco em como os diversos elementos da história estão ordenados" (Gray, 2012,p. 140). Essa análise possibilita interpretar evento e histórias revelando os pontos de vista do narrador. "É o estudo das vidas a partir da experiência do narrador, enfatizando o papel dessas narrativas para fortalecer pessoas por meio de um entendimento mais sutil de sua situação de vida" (Gray, 2012, p. 141).

A pesquisa foi desenvolvida com dois sujeitos adultos com TEA, ambos do sexo masculino, com idades de 28 e 30 anos, em acompanhamento em um Centro de Atenção Psicossocial (CAPS) do município de Maceió-AL, local de atenção que também acolhe/inclui sujeitos jovens e adultos com TEA. Este foi escolhido como forma de acesso a esses sujeitos que não mais estão em ambiente escolar.

Para promover as narrativas desses sujeitos foi utilizado o módulo de narrativas visuais (construção de histórias), do SCALA através de encontros individuais previamente agendados com os sujeitos em suas residências, com duração de duas horas, no mês de maio de 2016. Sendo respeitados os procedimentos éticos, estabelecidos na Resolução 466/2012, os sujeitos assinaram o Termo de Consentimento Livre e Esclarecido (TCLE) e foram caracterizados como: Sujeito 1 e Sujeito 2 respectivamente. Cada sujeito construiu suas histórias individuais, sem interrupção da pesquisadora que

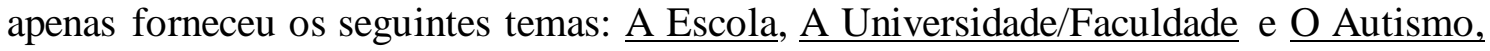
e posteriormente foram convidados a narrar sobre o conteúdo das histórias, os personagens inseridos e os significados das imagens.

A análise dos dados foi realizada a partir da análise de conteúdo, baseada em Bardin (2011), dos diários de campo, entrevistas, observações e produções postadas no SCALA quanto as significações das narrativas destacadas por Bertaux (2010). Com a 
V Congresso Brasileiro de Informática na Educação (CBIE 2016)

Anais do XXVII Simpósio Brasileiro de Informática na Educação (SBIE 2016)

finalidade de discutir a contribuição do SCALA na promoção de narrativas de sujeitos com TEA sobre as suas experiências escolares e o autismo.

\section{Resultados e Contribuições do SCALA}

\subsection{Sujeito 1}

Informações Gerais

Nascido no município de São Jerônimo-RS, foi adotado aos 6 meses de idade por um casal do município de Sapucaia do Sul-RS mudando-se para esta cidade. Os pais adotivos separam-se quando ele tinha seis anos passando a conviver com a sua mãe adotiva. As experiências escolares foram vividas nos Estados do Rio Grande do Sul e Alagoas quando mudou-se para Maceió-AL. Ingressou na escola aos dois anos de idade e finalizou o ensino médio aos 18 anos. Aos 23 anos ingressou no nível superior, passando pelos cursos de Direito (1 semestre), Turismo (2 semestres), Letras (1 semestre) e atualmente está concluindo o curso de História-Bacharelado em uma Universidade Pública e trabalha como embalador em uma loja de materiais de construção.

Os primeiros sinais de alteração no desenvolvimento foram percebidos por volta de um ano de idade pela mãe adotiva. Apresentou atraso para andar, por vezes "alheio ao mundo", não respondia aos chamados e nem olhava nos olhos das pessoas. Alfabetizouse sozinho por volta dos dois anos e meio de idade, recebendo o diagnóstico de Síndrome de Ásperger apenas aos 20 anos. Hoje tem 28 anos e oraliza adequadamente.

\section{$\underline{\text { As histórias construídas e seus significados }}$}

O Sujeito 1 contextualizou a escola (Figura 1) incluindo uma imagem representando a si próprio sentado e estudando. E outras imagens demonstrando o laboratório que existia na escola, os amigos e a professora e narrou:

A escola é importante, é onde a gente estuda. As escolas assim, onde eu fiz a educação básica, a gente tinha aula de química, física, biologia. Aí tinha o laboratório, é o lugar aonde a gente faz as amizades. E as professoras né? A gente não pode ser injusto né? Não pode discriminar um em detrimento de outro. Eu sou grato! Tem professora até hoje do ensino médio, que até hoje a gente tem contato. Fazer amizade com professor, qual o problema né? (Sujeito1).

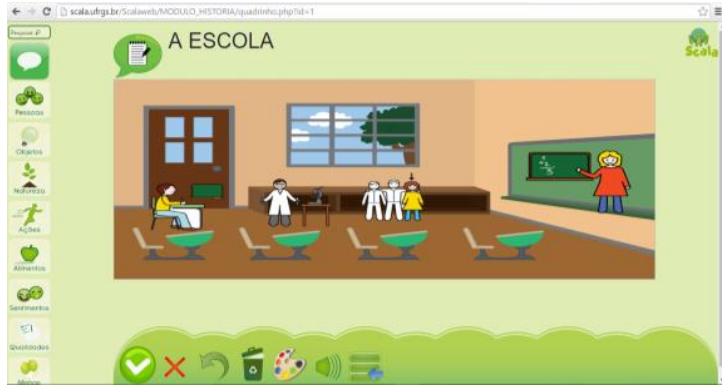

Figura 1. A Escola-Sujeito 1 Fonte: http://scala.ufrgs.br

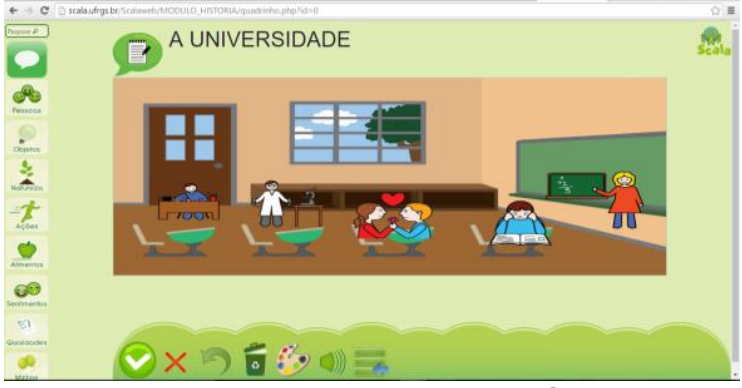

Figura 2. A Universidade-Sujeito 1 Fonte: http://scala.ufrgs.br 
V Congresso Brasileiro de Informática na Educação (CBIE 2016)

Anais do XXVII Simpósio Brasileiro de Informática na Educação (SBIE 2016)

Quanto a Universidade que frequenta atualmente, representou (Figura 2) os professores, a si próprio estudando e enfatizou como sendo um lugar também para o desenvolvimento da vida afetiva, onde se apaixonou por uma colega de um outro curso, mas que faz parte do mesmo bloco onde circulam. Sobre esse contexto relatou:

\begin{abstract}
Aqui é onde a gente estuda né? Aí você tem os professores, o apoio dos professores. Quando a gente chega assim... na faculdade, a gente logo pensa no professor universitário assim... Logo vê nos filmes, nas séries, a pessoa assim... bastante sisuda, compenetrada, mas não é pô! É gente igual a gente assim sabe? Eles não te olham de cima pra baixo. Te tratam como igual. Amizade com professor também tem, sabe? Mas naquele respeito, né? Limite né? Aí você tem aqueles professores que antes de chegar a faculdade também lecionou no ensino básico, também já lidou com aluno especial, ou que tem na família também, aí fica muito fácil. Aí quando você fala, a conversa flui. Duas professora lá que eu tenho maior estima, minha orientadora, ela tem um afilhado e outra tem um sobrinho autista. Só que o diagnóstico dele foi na infância e hoje faz Engenharia. Eu encaro também um provável lugar onde eu trabalho. Já pensou você estudar, trabalhar e pesquisar? (Sujeito1).
\end{abstract}

Sobre o autismo optou por um cenário de um ambiente externo (Figura 3), onde a primeira imagem representava a si, no processo de aceitação do diagnóstico do autismo, seguida de outras significando o apoio da família, os profissionais, a autonomia e os amigos. E narrou:

Primeiramente eu não me aceitava, não aceitava o autismo. Aqui sou eu aceitando o autismo junto aos colegas. Hoje, eu encaro o autismo não como um problema, uma sentença de morte, sabe? Não é uma doença, uma cruz que a gente carrega, eu encaro numa boa, não tenho "neura" quanto a isso. Tanta gente assim que tem, que foi diagnosticado com autismo e chegaram aonde chegaram..." (Sujeito1).

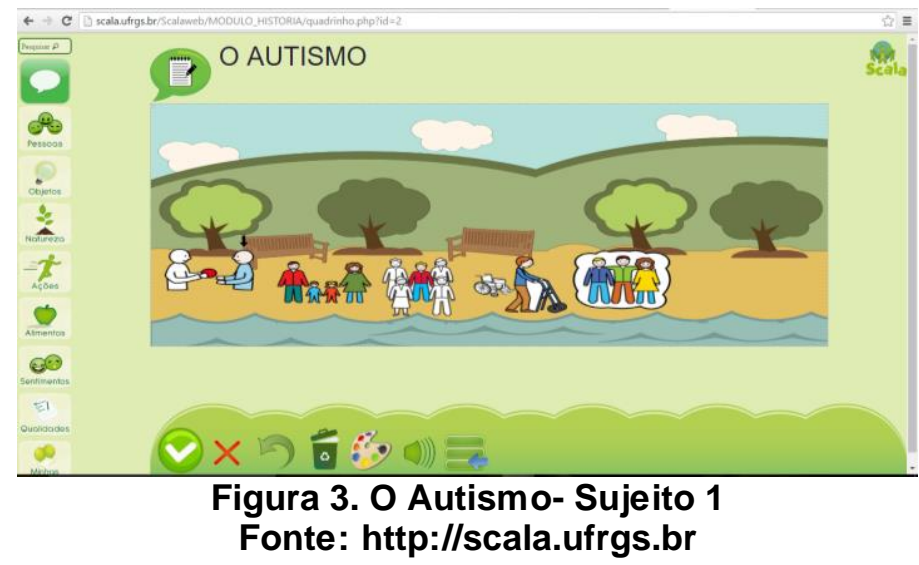

\title{
5.2 Sujeito 2
}

Informações Gerais

Nascido no município de Maceió-AL, possui uma irmã mais velha e um irmão mais novo, convivendo atualmente com este último e sua mãe biológica, pois seus pais separaram-se quando tinha seis anos de idade. As experiências escolares foram vividas no município de Maceió-AL, ingressando na escola aos dois anos de idade e finalizou o ensino médio 
V Congresso Brasileiro de Informática na Educação (CBIE 2016)

Anais do XXVII Simpósio Brasileiro de Informática na Educação (SBIE 2016)

aos 17 anos. Aos 18 anos ingressou no nível superior, passando pelos cursos de Zootecnia ( 1 semestre) e Contabilidade ( 2 semestres), mas desistiu no mesmo ano em que ingressou. Nunca trabalhou e atualmente passa a maior parte do tempo em sua residência deslocando-se apenas para a natação.

Os primeiros sinais de alteração no desenvolvimento foram percebidos por volta de um ano de idade pela mãe em comparação com a irmã mais velha. Era muito parado, apático e foi retardando a fala a medida em que foi crescendo. Alfabetizou-se sozinho por volta dos dois anos e meio de idade, recebendo o diagnóstico de Autismo Infantil apenas aos 30 anos, idade que possui atualmente. Oraliza apenas sob estímulo.

\section{As histórias construídas e seus significados}

O Sujeito 2 representou a escola (Figura 4) utilizando imagens referindo-se a si próprio, os colegas de turma e o professor. Outras imagens representavam os seus sentimentos quanto ao espaço escolar como: difícil, tedioso e feliz. Relatando: "Achava difícil a matemática", "Ficava com tédio das aulas", "Ficava feliz com a bagunça dos meus colegas” (Sujeito2).

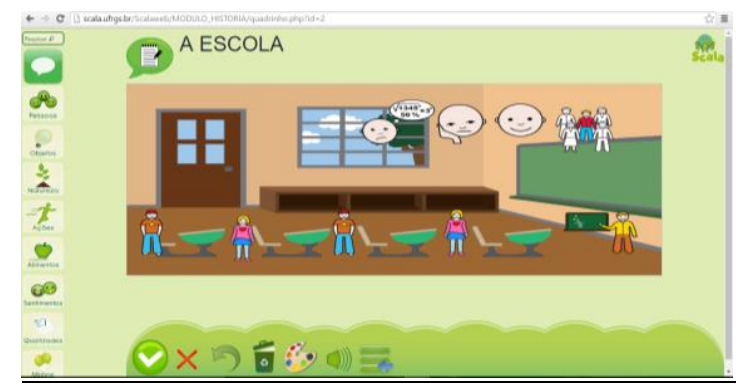

Figura 4. A Escola- Sujeito 2 Fonte: http://scala.ufrgs.br

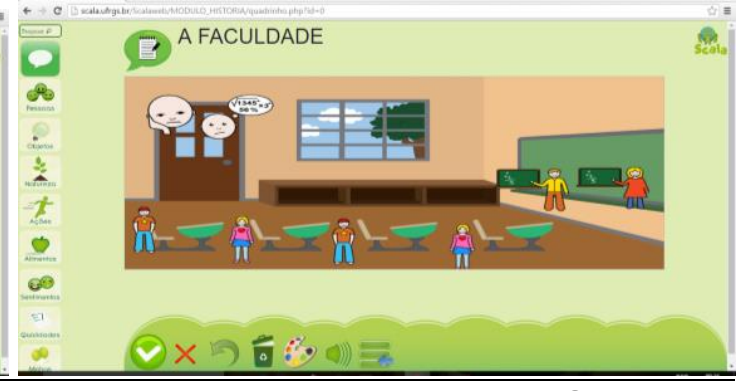

Figura 5. A Faculdade- Sujeito 2 Fonte: http://scala.ufrgs.br

O cenário da faculdade (Figura 5) também foi representado com imagens referindo-se a si próprio, os colegas de turma, o professor e uma professora. Os sentimentos representados foram: tedioso e difícil. E explicou: "Não gostava das aulas", "Era difícil a matemática". Referindo-se às aulas do curso de Contabilidade. Mas completou: "Eu gostava da faculdade" (Sujeito2).

Quanto ao autismo também escolheu um cenário representando um ambiente externo (Figura 6). E colocou sentimentos como: duvidoso, distraído, feliz, sério e tedioso. Narrou o seguinte: "É confuso. O Eduardo tinha esse negócio de Ásperger e era distraído". "Esse feliz é o Térsio! Ele era meu amigo, ele era alegre, gostava da TV, desse Sílvio Santos". Referindo-se a dois colegas do CAPS. Quanto ao sério e tedioso respondeu: "Sei lá! Eu" (Sujeito 2). 


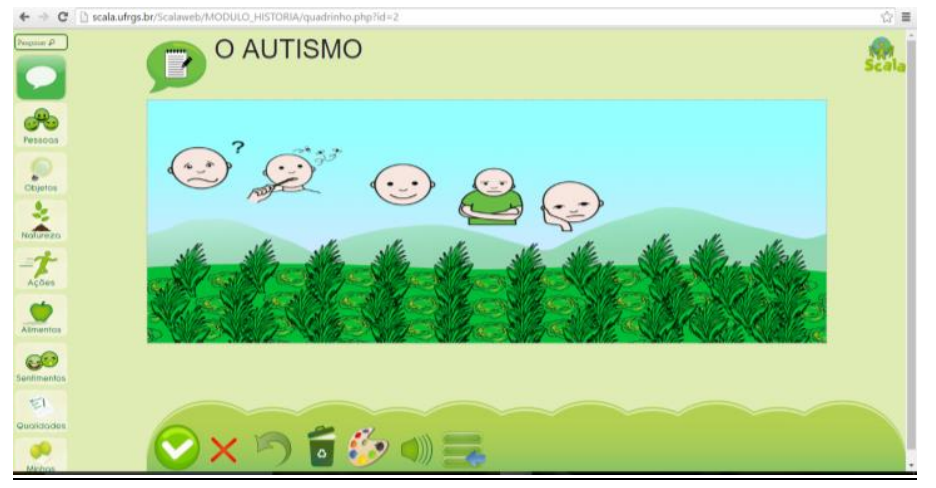

Figura 6. O Autismo- Sujeito 2

Fonte: http://scala.ufrgs.br

\subsection{Contribuições do SCALA}

A atividade estimulou suas memórias quanto aos acontecimentos, possibilitando às pesquisadoras conhecerem personagens significativos nas histórias dos sujeitos. Possibilitou a expressão dos sujeitos, um momento reflexivo sobre as experiências e inclusive sobre o SCALA, quando um dos sujeitos relatou de forma espontânea as contribuições da ferramenta:

Gostei! Até já indiquei! Indiquei o link para uma colega de trabalho que tem um filho autista de doze anos. Ela fez o cadastro. Olha, foi uma ideia! Quem, quem idealizou tá de parabéns! Porque vai ajudar e muito! Vai ser uma ferramenta de mão cheia. Não só para quem é autista, para criança que está na idade de alfabetização, ou quem tem dificuldade de aprender, de se expressar. Não vai ajudar só o autista em si. Gostei! Facilita! Pra se expressar ainda mais! (Sujeito 1).

Assim como foi evidenciado por Bez et al. (2013a), proporcionou entusiasmo e satisfação ao uso e mostrou-se como efetiva ferramenta de apoio a comunicação. Através do SCALA foi possível promover a produção de narrativas dos sujeitos com TEA sobre as suas experiências escolares e o autismo, pois mesmo sendo sujeitos oralizados, o processo de construção de histórias proporcionou uma maior riqueza de detalhes anteriormente não relatadas na técnica da entrevista narrativa sobre essas experiências.

\section{Considerações finais}

No tocante a relevância e originalidade, pode-se descrever que estudos que envolvam sujeitos adultos com TEA produzindo narrativas sobre as suas experiências escolares e autismo apoiados à tecnologia assistiva, de comunicação alternativa, com ações mediadoras na construção das referidas experiências, são pouco explorados nas pesquisas.

Espera-se contribuir na atenção desses sujeitos de forma a possibilitar um espaço para que se expressem, para possam falar em "primeira pessoa" sobre as experiências que lhes dizem respeito, pois o sujeito da educação precisa ser ouvido, seja ele deficiente ou não deficiente. Na particularidade desse estudo, pode-se refletir sobre esse processo para os demais sujeitos com TEA e sobre a importância de disponibilizar um sistema de comunicação alternativa no intuito de aumentar o potencial de comunicação desses sujeitos, a exemplo do que foi alcançado com o uso do SCALA. Além disso, colaborar no processo de ensino/aprendizagem desses sujeitos, onde o processo de escolarização ainda está em ressignificação de práticas sendo necessário buscar compreender os significados destas para os sujeitos da educação. 
V Congresso Brasileiro de Informática na Educação (CBIE 2016)

Anais do XXVII Simpósio Brasileiro de Informática na Educação (SBIE 2016)

\section{Referências}

Apa. (2013). American Psychiatric Association. Diagnostic and statistical manual of mental disorders. 5. ed. Washington, D. C.: American Psychiatric Association. Disponível em: http://www.terapiacognitiva.eu/dwl/dsm5/DSM-5.pdf. Acesso: 18 jun. 2015.

Bardin, L. (2011). Análise de conteúdo. São Paulo: Edições 70.

Bertaux, D. (2010). Narrativas de vida: a pesquisa e seus métodos. Tradução: Zuleide Alves Cardoso Cavalcante, Denise Maria Gurgel Lavallée; revisão científica Maria da Conceição Passeggi, Márcio Venício Barbosa. Natal, RN: EDUFRN, São Paulo: Paulus.

Bez, M. R. et al. (2013a). Desenvolvimento de narrativas visuais no SCALA: estudo de caso de uma turma de inclusão da Educação Infantil. Informática na Educação: teoria e prática. Porto Alegre, v. 16, n. 2, jul./dez.

(2013b). Relato de experiência: uso do SCALA em turma inclusiva. In: Congresso Brasileiro de Comunicação Alternativa, Gramado/RS. Anais V Congresso Brasileiro de Comunicação Alternativa: comunicar para incluir, v. 1. p. 1-16.

Bez, M. R.; Passerino, L. M. (2012). Scala 2.0: software de comunicação alternativa para web. AVANCES Investigación en Ingeniería, v. 9, n. 1.

Brasil. (2009). Decreto $n^{o}$ 6.949, de 25 de agosto de 2009. Disponível em: http://www.planalto.gov.br/ccivil_03/_ato2007-2010/2009/decreto/d6949.htm.

Acesso: 14 set. 2014.

Brasil. (2012). Lei $n^{o}$ 12.764, de 7 de dezembro de 2012. Disponível em: http://www.planalto.gov.br/ccivil_03/_ato2011-2014/2012/lei/112764.htm. Acesso em: 12 set 2014 .

Charlot, B. (2005). Prólogo. Introdução Bernard Charlot: uma relação com o saber; A Problemática da relação com o saber. In: Formação de professores e globalização. Porto Alegre: Armed.

Chiote, F. A. (2013). Inclusão da criança com autismo na educação infantil: trabalhando a mediação pedagógica. Rio de Janeiro: Wak Editora.

Cid-10. (2008). Classificação Estatística Internacional de Doenças e Problemas Relacionados à Saúde. 10 $0^{\mathrm{a}}$ Revisão, v. 1. Disponível em: http://www.datasus.gov.br/cid10/V2008/cid10.htm. Acesso: 18 jun. 2015.

Farias, I. M.; Maranhão, R. V.; Cunha, A. C. (2008). Interação professor-aluno com autismo no contexto da educação inclusiva: análise do padrão de mediação do professor 
V Congresso Brasileiro de Informática na Educação (CBIE 2016)

Anais do XXVII Simpósio Brasileiro de Informática na Educação (SBIE 2016)

com base na teoria da Experiência de Aprendizagem Mediada (Mediated Learning Experience Theory). Rev. bras. educ. espec. vol.14 no.3 Marília Sept./Dec. Disponível em: http://www.scielo.br/pdf/rbee/v14n3/v14n3a04.pdf. Acesso em: 25 dez. 2013.

Gray, D. E. (2012). Pesquisa no mundo real. 2. Ed. Porto Alegre: Penso.

Klin, A. (2006). Autismo e síndrome de Asperger: uma visão geral. Rev Bras Psiquiatr. 28(Supl I):S3-11. Disponível em: http://www.scielo.br/scielo.php?script=sci_arttext\&pid=S1516-44462006000500002. Acesso: 18 jun. 2015.

Korbivcher, Célia F. (2007). Bion e Tustin. Os fenômenos autísticos e o referencial de Bion: uma proposta de aproximação. Revista Brasileira de Psicanálise. v. 41, n. 2, 5462. Disponível em: http://pepsic.bvsalud.org/pdf/rbp/v41n2/v41n2a06.pdf. Acesso: 18 jun. 2015.

Lima, R. C. (2014). A construção histórica do autismo (1943-1983). Ci. Huma. e Soc. em Rev. RJ, EDUR, vol. 36, 1, jul / dez, p. 109 - 123. Disponível em: http://www.ufrrj.br/SEER/index.php?journal=chsr\&page=article\&op=view \&path $\% 5$ B\%5D=1031. Acesso: 18 jun. 2015.

Marfinati, Anahi C; Abrão, Jorge L. (2014). Um percurso pela psiquiatria infantil: dos antecedentes históricos à origem do conceito de autismo. Estilos clin., São Paulo, v. 19, n. 2, mai./ago, 244-262. Disponível em: http://pepsic.bvsalud.org/scielo.php?script=sci_arttext\&pid=S141571282014000200002 . Acesso: 18 jun. 2015.

Passerino, L. M. et al. (2013). SCALA e Siesta Cloud: uma integração para aplicações homeschooling visando a inclusão. Anais do II Congresso Brasileiro de Informática na Educação (CBIE 2013) e XXIV Simpósio Brasileiro de Informática na Educação (SBIE 2013).

Passerino, L. M.; Ávila, B. G.; Bez, M. R. (2010). SCALA: um Sistema de Comunicação Alternativa para o Letramento de Pessoas com Autismo. Renote, Novas Tecnologias na Educação, CINTED-UFRGS, v. 8, n. 2, julho. Disponível em: seer.ufrgs.br/renote/article/download/15224/8987. Acesso: 18 jun. 2015. 